\title{
Effect of listing strategies on utilization of antitumor necrosis factor biologics infliximab and etanercept: a cross-sectional analysis from Ontario, Canada
}

Jennifer Fenna, BScPharm, MHS; Daniel McCormack, MSc; Sophie Kitchen, MSc; Diana Martins, MSc; Tara Gomes, MHSc, PhD; and Mina Tadrous, PharmD, PhD

\section{What is already known about this subject}

- Biologic drug utilization continues to increase, yet uptake of biosimilars remains low despite their availability.

- Greater use of biosimilars can help health care systems to maintain access to effective and safe biologic therapies, while addressing system pressures due to the high cost of these therapies.

- A better understanding of the impact of differing policies will help to inform strategies aimed to improve biosimilar uptake.

\author{
What this study adds \\ - Traditional formulary policies on their \\ own are not effective in affecting \\ biosimilar uptake; low uptake in \\ comparison with other jurisdictions \\ highlights the need for additional \\ policies. \\ - Differences in biosimilar uptake by \\ indication highlights potential and \\ important differences that should \\ be accounted for in any policy \\ considerations. \\ - Effective policy approach requires \\ strong engagement and collaboration \\ with prescribers and patient groups to \\ understand the perspectives of those \\ affected by policy change.
}

\begin{abstract}
Author affiliations
Jennifer Fenna, BScPharm, MHS, Leslie Dan Faculty of Pharmacy, University of Toronto, Toronto, Canada, and Pharmacy Services, Alberta Health Services, Edmonton, Alberta, Canada. Daniel McCormack, MSc, ICES, Toronto, Canada. Sophie Kitchen, MSc, and Diana Martins, MSc, Li Ka Shing Knowledge Institute, Unity Health Toronto, Toronto, Canada. Tara Gomes, MHSc, PhD, Leslie Dan Faculty of Pharmacy, University of Toronto; Li Ka Shing Knowledge Institute, Unity Health Toronto; and Institute of Health Policy, Management and Evaluation, University of Toronto, Toronto, Canada. Mina Tadrous, PharmD, PhD, Leslie Dan Faculty of Pharmacy, University of Toronto; ICES; and Women's College Research Institute, Toronto, Canada.
\end{abstract}

AUTHOR CORRESPONDENCE:

Mina Tadrous, Mina.tadrous@wchospital.ca

J Manag Care Spec Pharm. 2021;27(4):444-52

Copyright $\odot 2021$, Academy of Managed Care Pharmacy. All rights reserved.

OBJECTIVE: To study the effect of formulary listing strategies on the use of infliximab and etanercept innovator and biosimilar biologics.

METHODS: This is a cross-sectional study of individuals in Ontario, Canada, dispensed a biologic prescription for infliximab or etanercept through Ontario's public drug program between January 1, 2010, and June 30, 2019. Quarterly utilization and costs were forecasted using Holt-Winters' exponential smoothing models to the second quarter (Q2) of 2022. Secondary analyses explored utilization for rheumatic conditions (RC) and inflammatory bowel disease (IBD). 
RESULTS: From Q1 2010 to Q2 2019, infliximab and etanercept users increased by $75.7 \%$ ( $n=4,073$ to 7,158$)$, with a forecasted increase of $13.7 \%(\mathrm{n}=8,142 ; 95 \% \mathrm{Cl}=7,438-8,847)$ by Q2 2022. Biosimilar users represented $13.8 \%(n=539$ of 3,905$)$ of total infliximab users in Q2 2019 , although this differed by indication with $6.9 \%$ for IBD ( $n=187$ of $2,712)$ and $26.6 \%$ for $R C(n=203$ of 764$)$. Etanercept biosimilar users represented $20.2 \%$ ( $n=659$ of 3,256 ) of total etanercept users for RC in Q2 2019. Biologics expenditures increased $109.7 \%$ during the study, amounting to \$49.9 million in Q2 2019.

CONCLUSIONS: Despite differing reimbursement restrictions between innovator infliximab and etanercept biologics, the uptake of their biosimilars was low and not noticeably different in the treatment of RC. Dynamic policy strategies are needed to improve the uptake of biosimilars, particularly for IBD.

Biologic drugs have received considerable attention in recent years because of their increasing use in the treatment of chronic diseases and high associated costs. This has led to biologics disproportionately contributing to accelerating drug costs, which are placing an increasing economic burden on public payers. ${ }^{1,2}$ According to recent Canadian data, biologics accounted for $23 \%$ of total public drug spending in 2018, with antitumor necrosis factor (TNF) drugs used to treat rheumatic conditions (RC) and inflammatory bowel diseases (IBD) listed as the highest overall drug class by public drug program spending. ${ }^{2}$ As the patents of innovator biologic drugs begin to expire, there is an opportunity to provide financial sustainability by increasing the use of lower cost biosimilars. These biosimilar drugs are biologic products that are similar to the innovator biologic drug already authorized for sale, with no clinically meaningful differences in efficacy and safety, and at a lower cost.1,3

From 2009 to August 2020, there have been 25 biosimilars approved in Canada ${ }^{4}$; however, the national uptake of these agents relative to their innovator equivalents has remained low. ${ }^{2,5}$ In 2018, biosimilars accounted for only 2.3\% of biologic users and $2.6 \%$ of overall spending on biologics in Canada. ${ }^{2}$ For the anti-TNF drugs infliximab and etanercept, biosimilars accounted for only $4.7 \%$ of the total spending on these 2 drugs in 2018. ${ }^{2}$ Similarly, in the United States, biosimilar anti-TNFs represented only $3.5 \%$ of all anti-TNF prescriptions, ${ }^{6}$ although contributing factors, including cost and coverage aspects, may differ between countries. The overall uptake of biosimilars in North America remains much lower than Europe, which accounts for $80 \%$ of the biosimilar use globally. ${ }^{7}$ The 2 countries with the highest anti-TNF biosimilar uptake in Europe, Norway, and
Denmark, had biosimilar market shares of $82 \%$ and $90 \%$ in 2016, respectively. ${ }^{8}$

Public drug program formulary listing approaches for innovator biologics, such as listing with restricted criteria for use or exclusion from the formulary, are a means that have been implemented to promote appropriate and sustainable utilization of biologics ${ }^{9,10}$; however, their effects on biosimilar uptake are not well studied. In Canada's province of Ontario, infliximab and etanercept innovator biologics and their biosimilars have been made available on the Ontario Drug Benefit (ODB) program with different formulary restrictions (Table 1). Specifically, the etanercept innovator is listed as a Limited Use product, meaning it is available on the general formulary with a clinical note for physicians to adhere to; conversely, the infliximab innovator is listed on the Exceptional Access program, meaning it requires authorization before use from the Ontario Ministry of Health. ${ }^{11}$

For the purposes of this study, we investigated the overall use of etanercept and infliximab biologics and compared 2 different drug formulary listing policies and the uptake of their associated biosimilars.

\section{Methods}

\section{SETTING}

We conducted a population-based cross-sectional study of individuals living in Ontario, Canada, who were dispensed a biologic prescription for infliximab and etanercept, 2 antiTNF agents with marketed biosimilars, through the ODB program between January 1, 2010, and June 30, 2019. Ontario residents are eligible for public drug coverage through the ODB program if they are unemployed, receiving support for disability or home care services, have high prescription drug costs relative to net household income, reside in a long-term care facility, or are aged 65 years or older. ${ }^{11}$ Starting in January 2018, individuals aged less than 25 years were eligible for ODB under the Ontario Health Insurance Plan +(OHIP+) program; however, on April 1, 2019, the OHIP+ program changed to limit coverage to only those without a private insurance plan. Because this change meant that new OHIP+ beneficiaries between January 2018 and March 2019 were not aligned with future beneficiaries after April 1, 2019, they were excluded from the analysis. ${ }^{11}$

Infliximab, which is indicated for RC and IBD, had its first infliximab biosimilar listed on the ODB formulary in February 2016, and a second biosimilar was listed in September 2018. Etanercept, which is only indicated for $\mathrm{RC}$, has 2 biosimilars available on the ODB formulary; these were added in July and December 2017. 


\begin{tabular}{|c|c|c|c|c|c|c|c|c|}
\hline $\begin{array}{l}\text { Medication } \\
\text { (Generic } \\
\text { Name) }\end{array}$ & Brand Name & $\begin{array}{c}\text { Medical } \\
\text { Indication }^{\mathrm{a}}\end{array}$ & Route & $\begin{array}{l}\text { Type of } \\
\text { Biologic }\end{array}$ & $\begin{array}{c}\text { Earliest } \\
\text { Dispensing } \\
\text { Date from the } \\
\text { ODB }\end{array}$ & $\begin{array}{c}\text { ODB } \\
\text { Formulary } \\
\text { Listing Date }\end{array}$ & Current Listing ${ }^{\mathrm{b}}$ & $\begin{array}{l}\text { Drug Benefit } \\
\text { Price or Unit } \\
\text { Price per } \\
\text { Dosage Form, \$ }\end{array}$ \\
\hline \multirow[t]{3}{*}{ Infliximab } & Remicade & $R C \& I B D$ & IV & Innovator & $\operatorname{Jan} 2,2002$ & - & $\begin{array}{c}\text { Exceptional } \\
\text { Access Program }\end{array}$ & 987.56 \\
\hline & Inflectra & $R C \& I B D$ & & Biosimilar & Feb 26, 2016 & Feb 25, 2016 & Limited Use & 525 \\
\hline & Renflexis & RC \& IBD & & Biosimilar & Sept 27, 2018 & Sept 27, 2018 & Limited Use & 493 \\
\hline \multirow[t]{3}{*}{ Etanercept } & Enbrel & $\mathrm{RC}$ & SC & Innovator & May 2, 2001 & $\operatorname{Dec} 3,2008$ & Limited Use & 405.99 \\
\hline & Brenzys & $\mathrm{RC}$ & & Biosimilar & Aug 2, 2017 & Jul 31, 2017 & Limited Use & 241 \\
\hline & Elrezi & $\mathrm{RC}$ & & Biosimilar & Jan 15, 2018 & Dec 21, 2017 & Limited Use & 241 \\
\hline
\end{tabular}

Source: Adapted with permission from the Ontario Drug Policy Research Network.

${ }^{a} \mid \mathrm{BD}=$ Crohn's disease and ulcerative colitis; $R C=$ rheumatic arthritis, psoriasis, and psoriatic arthritis.

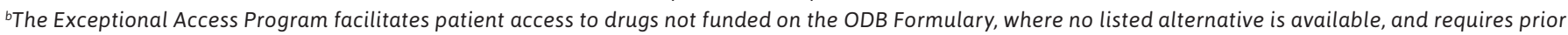
authorization. Limited use products require special clinical criteria/conditions to be met in order to be reimbursed under the ODB program but are generally available without a requirement of prior authorization.

$I B D=$ inflammatory bowel disease; IV = intravenous; $O D B=$ Ontario Drug Benefit; $R C=$ rheumatic conditions; $S C=s u b c u t a n e o u s$ administration.

\section{DATA SOURCES}

The ODB database was used for extraction of individual prescription claims for dispensed biologic and biosimilar prescriptions. This high-quality database has previously been shown to have an error rate of $<1 \%$ and allows linkage with other health administrative databases for obtaining patient demographic information..$^{12}$ Expenditures were reported as a separate variable in the database; costs of the drug, mark-up fees, dispensing fees, and deductible fees were summed to calculate total prescription cost.

Three health administrative databases were used to verify past diagnoses of RC and IBD. The Ontario Crohn's and Colitis Cohort (OCCC) dataset was used to determine past diagnoses of IBD (Crohn's and ulcerative colitis) ${ }^{13}$ along with the Ontario Rheumatoid Arthritis Database (ORAD) and the Ontario Psoriasis and Psoriatic Arthritis datasets for diagnoses of RC (rheumatoid arthritis, psoriasis, and psoriatic arthritis). ${ }^{14,15}$ The OCCC database has specificity in methods ranging from $96.2 \%$ to $99.5 \%$ and sensitivity based on patient age groups, ranging from $59.3 \%$ to $91.1 \%{ }^{11}$ ORAD includes only individuals aged over 15 years and has a specificity of $100 \%$ and sensitivity of $78 \%{ }^{11}$ The Psoriasis and Psoriatic Arthritis database has a specificity of $99 \%$ and $100 \%$ and a sensitivity of $52 \%$ and $51 \%$ for psoriasis and psoriatic arthritis, respectively. ${ }^{11}$

All of these databases use hospital and physician visits to identify past diagnoses. The Ontario Registered Persons Database (RPDB), Canadian Institute of Health Information Discharge Abstract Database (CIHI-DAD), National Ambulatory Care Reporting System (CIHI-NACRS) database, Ontario Health Insurance Plan (OHIP) database, and ICES Physician Database (IPDB) were used to determine patient and physician demographic characteristics and prescriber specialties. All databases used in this study were linked using unique encoded identifiers, and the analysis was completed at ICES using SAS Enterprise Guide, version 7.1 (SAS Institute, Cary NC).

\section{PRIMARY MEASURES}

We reported drug utilization of infliximab and etanercept biologics on a quarterly basis between January 1, 2010 (Q1 2010) and June 30, 2019 (Q2 2019). Quarterly trends from the previous 9 years were used to forecast trends in utilization between July 1, 2019 (Q3 2019) and June 30, 2022 (Q2 2022). Utilization was defined as the number of individuals who were dispensed a prescription for a biologic or biosimilar in each quarter. In a secondary analysis, we stratified utilization of each drug by patient indication, categorized as RC, IBD, and unknown.

Because the databases used to verify diagnoses only included cases up to March 31, 2018, individuals with new diagnoses after April 1, 2018, would not have been captured in the validated cohorts and thus were placed in the unknown diagnoses group. Individuals who received both biologics, or had both RC and IBD, in each quarter were counted in each subgroup. Expenditures were captured as net total claims costs to the ODB (in Canadian dollars), defined as the price of the drug plus mark-up fees, dispensing fees, and deductible fees. A sensitivity analysis was run with exclusion of deductibles and found no significant 


\section{FIGURE 1 Utilization of Infliximab and Etanercept Biologics Between 2010 and 2022}

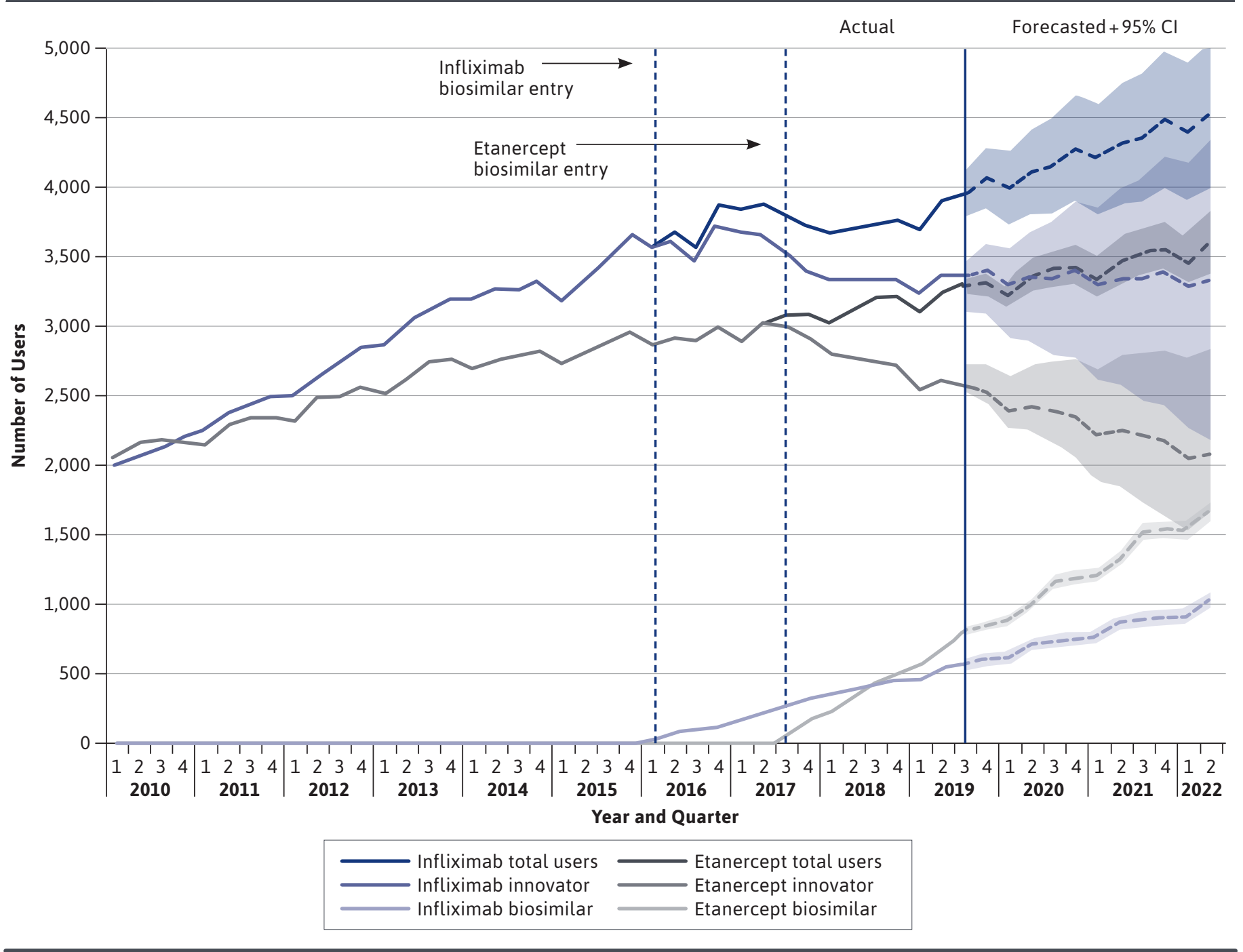

changes in the results (Supplementary Figure 2, available in online article).

\section{STATISTICAL ANALYSIS}

Descriptive statistics of utilization and costs and the percent increase during the study period was calculated. Forecasting of future utilization for overall innovator and biosimilar drugs were predicted using Holt-Winters' exponential smoothing models, with adjustment for current trends and seasonality. Additive or multiplicative method was used to achieve the best-fit model, which was used to predict overall utilization between July 1, 2019 (Q3 2019) and Q2 of 2022 with 95\% confidence intervals.

\section{Results}

\section{OVERALL UTILIZATION AND COSTS OF INFLIXIMAB AND ETANERCEPT BIOLOGICS FROM 2010 TO 2022}

Total utilization of infliximab and etanercept biologic drugs (innovator and biosimilar) increased by 75.7\% from Q1 2010 (4,073 users) to Q2 2019 (7,158 users) and is projected to increase by another $13.7 \%$ to 8,142 users (95\% CI=7,4388,847 ) by Q2 2022. By drug, over a period of 9 years, infliximab utilization increased by $93.5 \%$ (from 2,018 users in Q1 2010 to 3,905 users in Q2 2019), while etanercept utilization increased by 58.1\% (from 2,059 users in Q1 2010 to 3,256 users in Q2 2019; Figure 1). Infliximab was forecasted 


\section{FIGURE 2 Uptake of Etanercept and Infliximab Biosimilars by Indication}

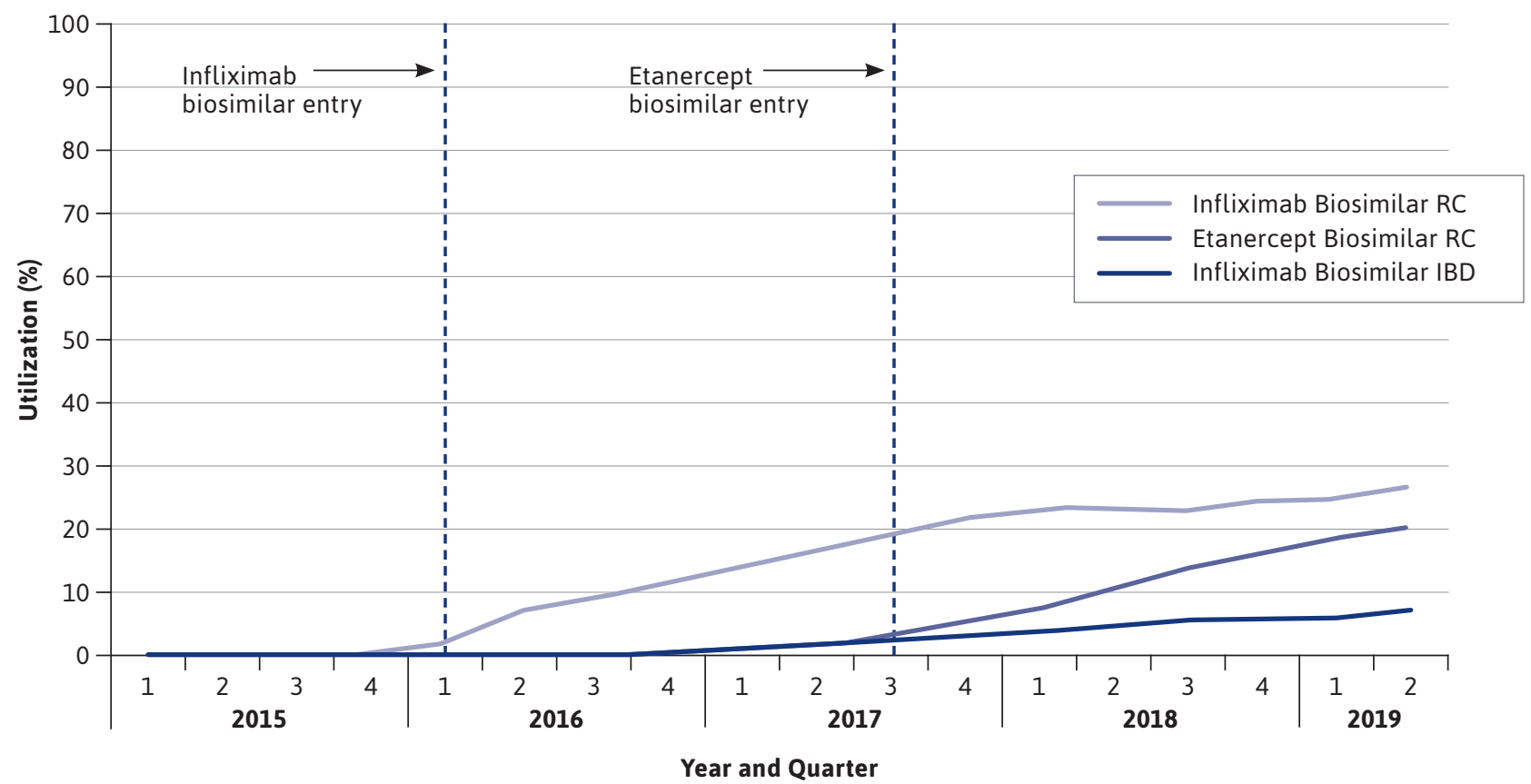

Note: Denominator is total users based on the specific indication represented.

$I B D=$ inflammatory bowel disease; $R C=$ rheumatic conditions.

to increase another $15.9 \%$ to 4,524 users $(95 \% \mathrm{CI}=3,993-$ $5,054)$ by Q2 2022, while etanercept was forecasted to increase $11.1 \%$ to 3,616 users $(95 \% \mathrm{CI}=3,417-3,816)$. The total costs of infliximab and etanercept biologics increased by 109.7\%, from \$23.8 million in Q1 2010 to $\$ 49.9$ million in Q2 2019 (Supplementary Figure 1, available in online article).

\section{UTILIZATION OF INNOVATOR BIOLOGICS AND BIOSIMILAR INFLIXIMAB AND ETANERCEPT BY DRUG FROM 2010 TO 2019}

Following the introduction of the first infliximab biosimilar on the ODB formulary in Q1 2016 (Table 1 and Figure 1), biosimilar infliximab utilization increased to $4.34 \%$ ( $n=167$ of $3,847)$ total users by Q1 2017, 9.5\% ( $\mathrm{n}=349$ of 3,674$)$ users by Q1 2018, and reached 13.8\% ( $\mathrm{n}=539$ of 3,905) of total users by Q2 2019 (Supplementary Figure 3, available in online article). Infliximab innovator utilization represented 3,659 users in Q4 2015, but declined by 8.0\% following the introduction of biosimilars, reaching 3,368 users by Q2 2019.

The first biosimilar for etanercept was listed on the ODB formulary in Q3 2017 (Table 1 and Figure 1). Etanercept biosimilar utilization subsequently increased to represent $15.7 \%(n=507$ of 3,224) total users by Q3 2018 and 20.2\% ( $n=659$ of 3,256 ) total users (Supplementary Figure 4, available in online article) by Q2 2019. Etanercept innovator utilization reached 3,027 users in Q2 2017 but declined by 13.3\% following the listing of its biosimilar to 2,603 users in Q2 2019.

\section{UTILIZATION OF BIOSIMILAR ETANERCEPT AND INFLIXIMAB IN RC AND IBD FROM 2010 TO 2019}

Analyses of biosimilar utilization by clinical indication showed differences in uptake in RC and IBD conditions. In $\mathrm{RC}$, infliximab biosimilar utilization reached $26.6 \%(\mathrm{n}=203$ of 764 total users) in Q2 2019 (Figure 2 and Supplementary Figure 5, available in online article), while etanercept biosimilar utilization was $20.2 \%$ ( $n=659$ of 3,256 total users; Figure 2 and Supplementary Figure 6 , available in online article). In IBD, infliximab biosimilar utilization had reached 6.9\% (187 of 2,712 total users) in Q2 2019 (Figure 2 and Supplementary Figure 7, available in online article), while etanercept was not indicated for IBD. 


\section{Discussion}

Although access to innovator infliximab is restricted in an enforced manner (i.e., prior authorization required) compared with innovator etanercept where restrictions are passively enforced, the uptake of their respective biosimilars does not differ greatly. Differences between the 2 formulary policies are that for a patient to have coverage under prior authorization, the prescriber must submit a prior authorization to the ODB with clinical rationale as to why formulary benefits are not suitable and how they match prespecific criteria. Drugs with limited use criteria are technically listed for specific indications but are generally available on the formulary without prior authorization (e.g., off-label indications). Biosimilar use is also notably higher when used for $\mathrm{RC}$, representing almost a quarter of users in 2019, compared with IBD where biosimilar use represented less than 1 in 10 users. These findings reveal that traditional formulary listing mechanisms for biologic drugs may not lead to the desired or predicted shifts in utilization as compared with generic small molecule drugs, resulting in missed opportunities for optimizing cost savings with use of biosimilars. These results highlight important areas of focus, including understanding differences between indications and identifying a strong need for more timely and effective formulary policies and strategies to promote biosimilar uptake.

One of the considerations of our analysis was the difference in uptake of biosimilars based on indication, with greater utilization in RC populations compared with IBD populations. This observation highlights potentially important differences that should be accounted for in any policy consideration. While several studies have investigated biosimilar prescribing habits of gastroenterologists and rheumatologists, their results have not shown a clear pattern, and some unwillingness to prescribe biosimilars has been found in both prescriber groups. ${ }^{16}$ Potential reasons can range from clinical discomfort, negative perceptions, and hesitancy of prescribers and patients around the use of biosimilars. ${ }^{3,7,16-19}$

Historically, some concerns arose from the regulatory approval of biosimilar products that allows for authorization of use by extrapolation of therapeutic similarity from one indication to another.,16 For example, when the first marketed infliximab biosimilar became available, the extrapolation of data from studies conducted in patients with rheumatic diseases to bowel diseases was initially not applied because of differences in disease mechanisms. ${ }^{20,21}$ This may have contributed to the low uptake of infliximab biosimilars for IBD observed in our study. Further, since there are fewer biologics with biosimilars available for the treatment of IBD conditions than for $\mathrm{RC},{ }^{22}$ this may contribute to a lower uptake in this clinical area because of a lack of familiarity and experience with biosimilars. ${ }^{16}$

Our findings of differences between clinical indications may also reflect perceived policy gaps from the perspectives of those affected by policy change and a need for stronger engagement and collaboration with stakeholders. ${ }^{719}$ With the complexity of using biologics, there has been greater integration of patient support programs into clinical practice; in this regard, innovator biologics typically have well-established support programs with large number of infusion centers, making them more accessible and convenient to patients in more remote geographic areas or during evenings and weekends. ${ }^{11,19}$ This may affect infliximab more, since it has an intravenous route of delivery versus the subcutaneous route for etanercept. ${ }^{23}$ Improving consideration of factors associated with biologic administration and patient care can positively affect the quality of care associated with biosimilars and enhance the success of the policy approach.

Also of importance is ensuring that physicians and patients have adequate education and understanding of biosimilars, ${ }^{24}$ and optimizing the role that pharmacists may have in recommending biosimilars, since a lack of awareness and knowledge and associated negative attitudes can pose as barriers to biosimilar use., ${ }^{7,25}$ Education of physicians has been found to be effective in closing knowledge gaps, increasing confidence, and improving prescribing of biosimilars. ${ }^{7,16}$ For example, a study in Italy found a significant $14.4 \%$ increase in biosimilar filgrastim use after an educational intervention. ${ }^{26}$ Having precise, reliable, and clearly communicated information is key to facilitating informed decision making by physicians and patients. ${ }^{24,25,27}$

Educational policies that may effectively achieve this goal include providing hospital seminars, scientific conferences, practice guidelines, or continuing educational programs for physicians and information leaflets or letters for patients. ${ }^{16,25}$ However, implementing and measuring the effect of these education and other potential policy changes over time will be necessary to determine their effects and help guide strategies moving forward to continue to promote cost savings of biosimilars. While the experiences to date show some promising growth of biosimilar use over time, the full potential remains to be achieved.

Finally, our findings of an overall low uptake of biosimilars compared with other jurisdictions highlight the need for dynamic policy strategies compared with the existing traditional drug listings currently in place. Lessons can be drawn from other jurisdictions internationally and within Canada. ${ }^{8,18,25,28}$ Some of the potential policies include broader tendering policy (competitive bidding process), retail and 
hospital contracts, mandating substitution of innovator biologics with biosimilars, only reimbursing biosimilars for newly diagnosed persons, and using a tiered reimbursement strategy (requiring the most cost-effective innovator biologics and biosimilars to be used first) for access to either innovator or biosimilar biologics. ${ }^{18,25}$

These policies, when used individually or in combination, can have significant positive effects. ${ }^{8}$ For example, by using hospital, regional, and national tendering, Denmark's utilization of anti-TNF biosimilars reached $90 \%$ of market share in 2016 , only 1 year after the entry of the biosimilar. ${ }^{8}$ In contrast, biosimilar uptake in Sweden, where subcutaneous drug product pricing is determined by managed entry agreements, but physicians are free to choose the most suitable product for their patient in consideration of costs, is highly variable between regions, ranging from $30 \%$ to $83 \%$ for etanercept. ${ }^{24}$

Several jurisdictions in Canada have recently adopted different approaches to improve biosimilar uptake on public drug plans. This includes Manitoba (tiered reimbursement), ${ }^{29}$ British Columbia (switching of patients from specific innovator to biosimilar products), ${ }^{30}$ and most recently Alberta (tiered reimbursement and switching to be implemented by January 2021). ${ }^{31}$ These policy changes are anticipated to, and have already indicated that they will, improve biosimilar uptake ${ }^{32}$ and should be considered in Ontario and other jurisdictions in Canada, as well as globally to further improve uptake and reduce costs.

\section{LIMITATIONS}

The main limitations of this study are in relation to its population-based study design, which relies on data collected in the administrative databases being accurately detailed and coded. ${ }^{33}$ As discussed in the Methods section, because of changes in the OHIP+ coverage criteria between January 1, 2018, and April 1, 2019, we removed new beneficiaries from the study during this time. In addition, in the analysis of $\mathrm{RC}$ and IBD indications, patients with new diagnoses after March 31, 2018, were placed into an unknown diagnoses group because information on diagnosis was not available after this date in the available databases. Thus, there may be some underestimation of drug utilization, associated expenditures, and patient diagnoses during these time frames.

Forecasting of trends in utilization and costs are based on currently approved biosimilars and may not accurately predict the effect of approval of additional biosimilars on expenditures or uptake. Information on pricing is based on claims submitted by pharmacies to the ODB and may not reflect actual pricing paid through confidential listing agreements with manufacturers. Also, our study results may not be generalizable to all jurisdictions, depending on similarities or differences in national or regional drug reimbursement policies as well as population characteristics.

Finally, results of the study should be interpreted as descriptive in nature in consideration of the study design and potential factors outside of formulary restrictions that may have affected biosimilar uptake that were not statistically analyzed.

\section{Conclusions}

Biosimilars may help curb the pressures on payers from rising costs associated with growing biologic use but are currently underused, which is concerning for payers given the rapidly increasing utilization and costs of biologics. Strategies such as provision of biosimilar-specific education to clinicians and patients can help minimize knowledge gaps and improve comfort and familiarity with biosimilar products. Also, increased attentiveness to factors associated with biologic administration and patient care can further improve their acceptance. Traditional formulary management policies may not be enough to ensure optimal biosimilar uptake, thus, implementing more effective policy strategies, similar to other jurisdictions, will be essential to ensure the sustainability of biologic drug use moving forward.

\section{DISCLOSURES}

Funding for this study was contributed by the Ontario Ministry of Health. The authors have no conflicts of interest to disclose.

\section{REFERENCES}

1. Health Canada. Biosimilar biologic drugs in Canada: fact sheet. August 23, 2019. Accessed February 27, 2021. https:// www.canada.ca/content/dam/hc-sc/ migration/hc-sc/dhp-mps/alt formats/ pdf/brgtherap/applic-demande/guides/ Fact-Sheet-EN-2019-08-23.pdf

2. Canadian Institute for Health Information. Prescribed Drug Spending in Canada, 2019: A Focus on Public Drug Programs. Ottawa, ON: CIHI; 2019. Accessed March 8, 2021. https://www. cihi.ca/sites/default/files/document/ pdex-report-2019-en-web.pdf

3. Patented Prices Review Board. Poster 8. Biosimilars in Canada: current environment and future opportunity. PDF-647 KB. Modified October 29, 2019. Accessed February 27, 2021. http://www.pmprbcepmb.gc.ca/view.asp?ccid=1478\&lang=en

4. Wojtyra U. Canada: update on biosimilars in Canada - August 2020. August 27, 2020. Accessed February 27, 2021. https://www.mondaq.com/canada/ healthcare/980240/update-on-biosimilars-in-canada-august-2020 
5. Mansell K, Bhimji H, Eurich D, Mansell H. Correction to: Potential costsavings from the use of the biosimilars filgrastim, infliximab and insulin glargine in Canada: a retrospective analysis. BMC Health Serv Res. 2019;19(1):972. doi:10.1186/ s12913-019-4829-z

6. Bansback N, Curtis JR, Huang J, et al. Patterns of tumor necrosis factor inhibitor (TNFi) biosimilar use across United States rheumatology practices. ACR Open Rheumatol. 2020;2(2):79-83. doi:10.1002/ acr2.11106

7. Sarnola K, Merikoski M, Jyrkkä J, Hämeen-Anttila K. Physicians' perceptions of the uptake of biosimilars: a systematic review. BMJ Open. 2020;10(5):e034183. doi:10.1136/bmjopen-2019-034183

8. QuintilesIMS. The impact of biosimilar competition in Europe. May 2017.

Accessed February 27, 2021. https:// www.medicinesforeurope.com/ wp-content/uploads/2017/05/ IMS-Biosimilar-2017 V9.pdf

9. Lucio SD. Biosimilars: Implications for health-system pharmacists. Am J Health Syst Pharm. 2013;70(22):2004-17. doi:10.2146/ajhp130119

10. Tadrous M, Knowles S, Ruddock B, et al. Comprehensive Drug-Class Review Framework for improved evidence-based drug policy and formulary modernization. Int J Technol Assess Health Care. 2020;36(1):12-19. doi:10.1017/ S0266462319000746

11. Tadrous M, McCormack D, Martins D, Kitchen S, Singh S, Gomes T. Current and prospective utilization of innovator biologics and biosimilars in Ontario. A report by the Ontario Drug Policy Research Network. January 2020. doi:10.31027/ ODPRN.2020.01

12. Levy AR, O'Brien BJ, Sellors C, Grootendorst P WD. Coding accuracy of administrative drug claims in the Ontario Drug Benefit database. Can J Clin Pharmacol. 2003;10(2):67-71.
13. Benchimol EI, Guttmann A, Mack DR, et al. Validation of international algorithms to identify adults with inflammatory bowel disease in health administrative data from Ontario, Canada. J Clin Epidemiol. 2014;67(8):887-96. doi:10.1016/j.jclinepi.2014.02.019

14. Widdifield J, Bernatsky S, Paterson JM, et al. Accuracy of Canadian health administrative databases in identifying patients with rheumatoid arthritis: a validation study using the medical records of rheumatologists. Arthritis Care Res. 2013;65(10):1582-91. doi:10.1002/acr.22031

15. Eder L, Widdifield J, Rosen CF, et al. Trends in the prevalence and incidence of psoriasis and psoriatic arthritis in Ontario, Canada: a population-based study. Arthritis Care Res. 2019;71(8):108491. doi:10.1002/acr.23743

16. Leonard E, Wascovich M, Oskouei S, Gurz P, Carpenter D. Factors affecting health care provider knowledge and acceptance of biosimilar medicines: a systematic review. J Manag Care Spec Pharm. 2019;25(1):102-12. doi:10.18553/ jmcp.2019.25.1.102

17. van Overbeeke E, De Beleyr B, de Hoon J, Westhovens R, Huys I. Perception of originator biologics and biosimilars: a survey among Belgian rheumatoid arthritis patients and rheumatologists. BioDrugs. 2017;31(5):447-59. doi:10.1007/s40259-017-0244-3

18. Lončar M, de Leseleuc L, Ahuya T. Utilization of Innovator Biologics and Biosimilars for Chronic Inflammatory Diseases in Canada: A Provincial Perspective. CADTH Technology review: Optimal Use 360 report, no. 27. CADTH; 2020. Accessed March 8, 2021. https:// www.cadth.ca/sites/default/files/ou-tr/ ho0007-biosimilars-utilization-final.pdf

19. Kaplan GG, Ma C, Seow CH, Kroeker KI, Panaccione R. The argument against a biosimilar switch policy for infliximab in patients with inflammatory bowel disease living in Alberta. J Can Assoc Gastroenterol. 2020;3(5):234-42. doi:10.1093/jcag/gwz044
20. CADTH Common Drug Review. Subsequent entry biologic review report for Inflectra. November 2017. Accessed February 27, 2021. https://www.ncbi. nlm.nih.gov/books/NBK534737/pdf/ Bookshelf_NBK534737.pdf

21. Siu E, WG. Current state of subsequent entry biologics (biosimilars) in Canada: a view from regulatory, reimbursement, clinician, and patient perspectives. $\mathrm{GaBI}$ Journal. 2016;5(3):105-13. doi: 10.5639/ gabij.2016.0503.028

22. Kaida-Yip F, Deshpande K, Saran T, Vyas D. Biosimilars: review of current applications, obstacles, and their future in medicine. World J Clin Cases. 2018;6(8):161-66. doi:10.12998/wjcc. v6.i8.161

23. Augustovski F, Beratarrechea A, Irazola $\mathrm{V}$, et al. Patient preferences for biologic agents in rheumatoid arthritis: a discrete-choice experiment. Value Health. 2013;16(2):385-93. doi:10.1016/j. jval.2012.11.007

24. Reilly M, Schneider P. Policy recommendations for a sustainable biosimilars market: lessons from Europe. GaBI Journal. 2020;9(2):76-83. doi: 10.5639/ gabij.2020.0902.013

25. Moorkens E, Vulto AG, Huys I, et al. Policies for biosimilar uptake in Europe: an overview. PLoS One. 2017;12(12):1-17. doi:10.1371/journal.pone.0190147

26. Trotta F, Mayer F, Mecozzi A, Amato L, Addis A. Impact of guidance on the prescription patterns of G-CSFs for the prevention of febrile neutropenia following anticancer chemotherapy: a population-based utilization study in the lazio region. BioDrugs. 2017;31(2):117-24. doi: 10.1007/s40259-017-0214-9

27. Frantzen L, Cohen JD, Tropé S, et al. Patients' information and perspectives on biosimilars in rheumatology: a French nation-wide survey. Jt Bone Spine. 2019;86(4):491-96. doi:10.1016/j. jbspin.2019.01.001 
28. Rémuzat C, Kapuśniak A, Caban A, et al. Supply-side and demand-side policies for biosimilars: an overview in 10 European member states. J Mark Access Heal Policy. 2017;5(1):1307315. doi:10.1080/2 0016689.2017 .1307315

29. Manitoba Health. Tiered biologics reimbursement policy tiered biologics reimbursement policy flowsheet. Effective August 15, 2018. Bulletin \#100. Accessed February 27, 2021. https://www.gov. mb.ca/health/mdbif/docs/bulletins/bulletin100.pdf
30. Government of British Columbia. Biosimilars Initiative for Patients. Accessed February 27, 2021. https:// www2.gov.bc.ca/gov/content/ health/health-drug-coverage/ pharmacare-for-bc-residents/ what-we-cover/drug-coverage/ biosimilars-initiative-patients

31. Alberta Government. Biosimilar drugs. Accessed February 27, 2021. https://www. alberta.ca/biosimilar-drugs.aspx
32. Fisher A, Kim JD, Dormuth CR. Rapid monitoring of health services utilization following a shift in coverage from brand name to biosimilar drugs in British Columbia-an interim report. Pharmacoepidemiol Drug Saf. 2020;29(7):803-10. doi:10.1002/pds.5008

33. Thygesen LC, Ersbøll AK. When the entire population is the sample: strengths and limitations in register-based epidemiology. Eur J Epidemiol. 2014;29(8):551-58. doi:10.1007/s10654-013-9873-0 